\title{
Polyarticular Still Disease
}

National Cancer Institute

\section{Source}

National Cancer Institute. Polyarticular Still Disease. NCI Thesaurus. Code C61280.

Juvenile rheumatoid arthritis affecting multiple joints, usually symmetrically. It may be associated with low grade fever, anemia, and weight loss. Patients usually test negative for rheumatoid factor. 